\title{
Prospects, Challenges and Strategies of Rapid Agriculture Commercialiazation in Hilly Region
}

\author{
Yubraj khanal* \\ Agriculture and Forestry University, Rampur, Chitwan, Nepal \\ *Corresponding Author: Yubraj khanal, Agriculture and Forestry University, Rampur, Chitwan, Nepal.
}

Received: May 20, 2019; Published: June 14, 2019

DOI: 10.31080/ASAG.2019.03.0529

Nepal is a country of country of contrast with diversified topography, landforms and biodiversity within a difference of Four degree longitude. About $83 \%$ of total is occupied by 7 hills and mountains and is characterized by unique ecological entities and topographical diversities. The distinctive socio-economic features ethnicity, climatic variability and human activities demarcates hill and mountain ecosystem from the rest. The in accessiblity and difficulties marginalized the hill and mountain. These diverse topologies having difficult terrain, inaccessible habitation, extreme vulnerability to natural calamities, and poor infrastructure and gender stratification are the important features of agri-horti-silvi pastoral economics. This implies that hilly regions demand distinctive treatment that is different from the standard followed in the mainland plain area.

\section{Geophysical location of hilly region}

Hill region (called Pahar in nepali) is mostly between 1000$4000 \mathrm{~m}$ in altitudes. It includes the Kathmandu Valley, the country's most fertile and urbanized area. Two major ranges of hills, commonly known as Mahabharat and Shiwalik Range occupy the region. In addition, there are several intermediate valleys. The mid-hill region of Nepal which comprises about $42 \%$ of country's land area includes a wide range of micro-climate condition from warm subtropical to warm temperate. $43 \%$ people live in the region where mountain peaks range up to $2000 \mathrm{~m}$, with narrow river valleys. Higher peaks receives occasional snowfall, lower parts receive some frost in winter which damages the crop.

\section{Agriculture in Hill; Past and Present}

Agriculture in hilly region is generally performed in terraces (sculption of hill hill into massive complexes) by human hand, however these area is very small and less productive in comparison to the lower valleys which are densely populated. Since ancient times, marginal farmer in the hilly area have developed many techniques to increase production. Although cereals are mainly grown, nearly $80 \%$ area is occupied by rice, wheat and maize. The other crops grown are pulses, oilseed, millets, vegetables, and fruit crops. In the hills, crops such as buckwheat, saffron, black cumin are also grown. The major cropping system includes maize/wheat, rice/wheat, and intercropping of pulses and oilseeds in maize and wheat. Monoculture are prevalent in the higher hills where farming is possible only in summer, but at lower altitude rotational farming is traditional practiced, often a sequence of barley, peas and wheat, livestock, although an integral part of agriculture is secondary to crops. Climate varies from sub-tropical to warm temperate. Cattle, buffalo, goats are major grazing livestock. Hill farming systems are true example of crop-livestock integrations utilizes forest resources for fodder. For early vegetative productions and capturing the profitable early market for growers are now using plastic tunnel or hot caps. In additions some farmers has initiated using plastic mulches in combination with tunnels to speed up the harvest date for some crops. Non-conventional irrigation system is also being adopted. Both government agencies and NGOs are promoting nonconvention irrigation system such as drip and sprinkler irrigation.

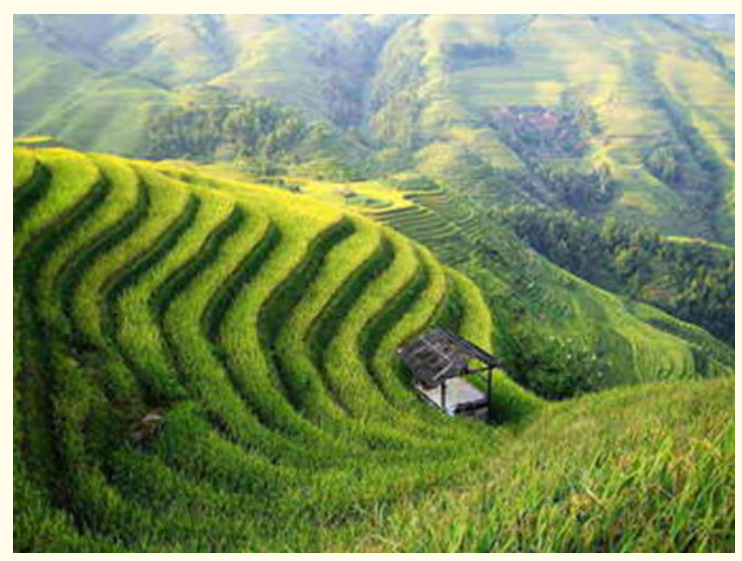

Figure 1 
Prospects of agriculture commercialization

Since the region ahs wide range of physiographic, soil and biological diversity, there is huge scope to intensify existing cropping system through diversification, either by crop rotation pr intercropping. Besides these, there are various prospects of agriculture commercialization some of them are;

\section{Horticulture}

Large no of fruits, vegetables, spices, medicinal and aromatics plants can be grown with relative advantage due to availability of warm tropical to warm temperate climates. Crops like potato, cabbages, turnips etc can be produced in large scale through farm mechanization. Plum, peaches, citrus and some non-perishable crops like pecanuts, kiwi etc can be grown. Tea and cardamom can be grown in eastern hilly region.

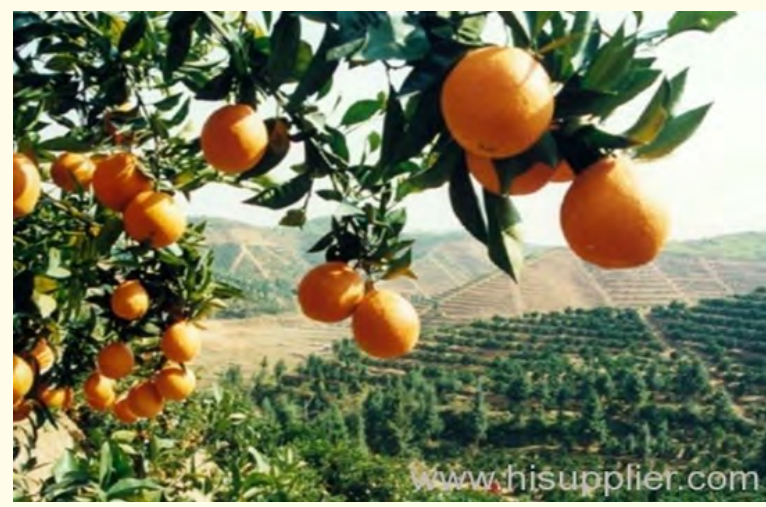

Figure 2

\section{Livestock}

Since, most of the area is unsuitable to carry out agricultural operations, various shed house and housing to rear animals could be constructed. The underfertilized land can be supplemented by animal byproducts and manner as source of fertilizers. Likewise, the animal could be raised by nomadic grazing in high pastoral land.

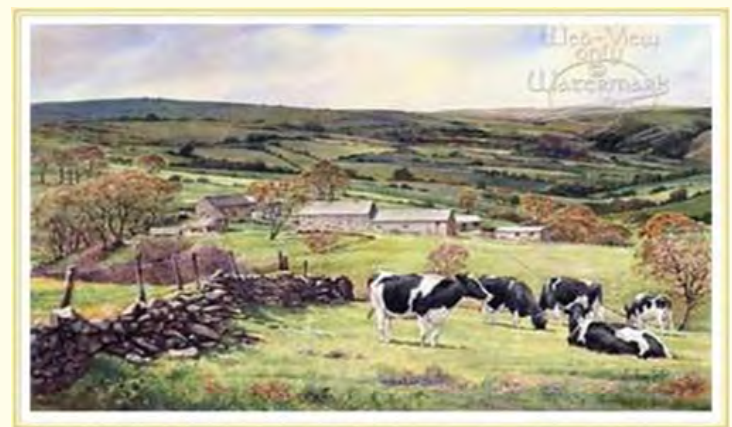

Figure 3
Agro-forestry

Agri-silvicultural practices could be done. A traditional homestead or home garden with large number of tree species raised for livestock, poultry or fish, have high value. In a home garden multiple crops are present in multi-tier canopy. Homestead posses fodder tree like Bahunia varigata, in the upper storeyed followed by Adatodsa viscia, Vitex negudo and lemon tree as fruit in middle storey with cucurbit vines like colocaisa, turmeric vegetable etc could be grown.

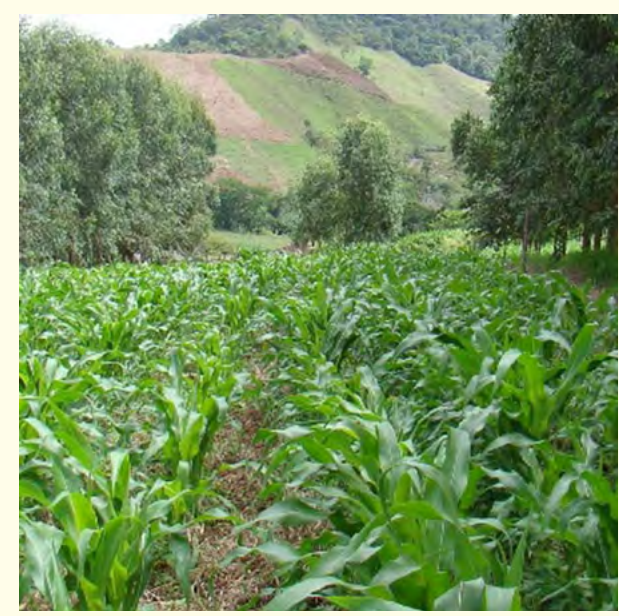

Figure 4

\section{Protected cultivation}

In order to encourage early vegetable productions and capture, the early profitable market, growers can use protected structures like green house, plastic tunnel, micro-irrigation, plastic mulching and plastic punnets for packing a materials for proper marketing.

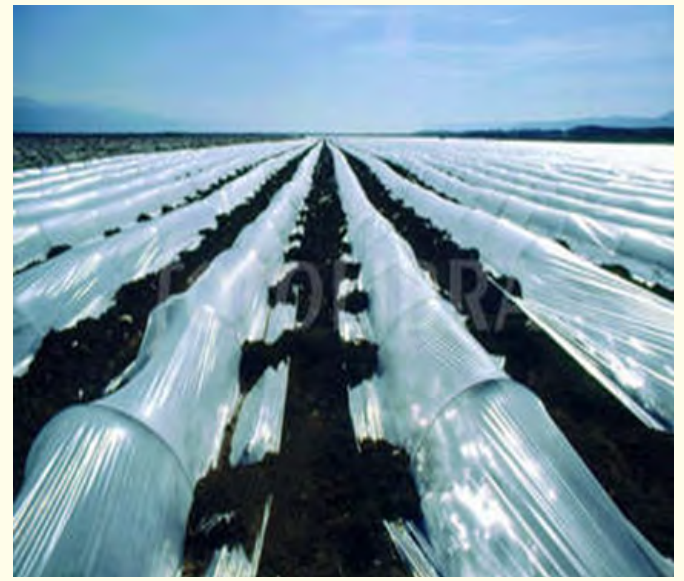

Figure 5 


\section{Reserve of genetic variations}

Hills and mountains is the richest reservoir vector of genetic variation and a large stock of little known crops. These could be used as rootstock for various fruit and flower crops. Similarly, by the marketing of such wild varieties of medicinal and ornamental plants uncommon opportunities could be reaped.

\section{Challenges in commercialization of agriculture}

Although subsistence agriculture is undergoing transformation un some pocket areas of more from crop diversification, horticulture and cash crops. Commercial farming is far from the norms. There are many reason behind this:

- Land is undulating and inaccessible so infrastructure, com munication and mobility are obstructed by different physi cal, climate, biological and socio-economic factors.

- Sloppy soils are in the verse of erosion, which is assisted by heavy migratory grazing.

- Undulating topography, small fragmented and scattered land holdings with very limited use of inputs.

- Soil is shallow and stony and subjects to periodic water stress.

- Irrigation facilities are limited and most agriculture depends on rainfall.

- Improved technology has largely been confined to irrigated lands.

- Shortage of energy and labours.

- Natural hazards like intense rainstorms, hailstorms, floods, epidemic diseases, insects.

- Reduction in areas of cultivable land due to house construc tion and use for non-agriculture operation.

- Lack of priority in improving farming on slopping lands.

- Tribal farmers depend on their traditional knowledge and constrainted by inclement terrain.

- Widespread poverty

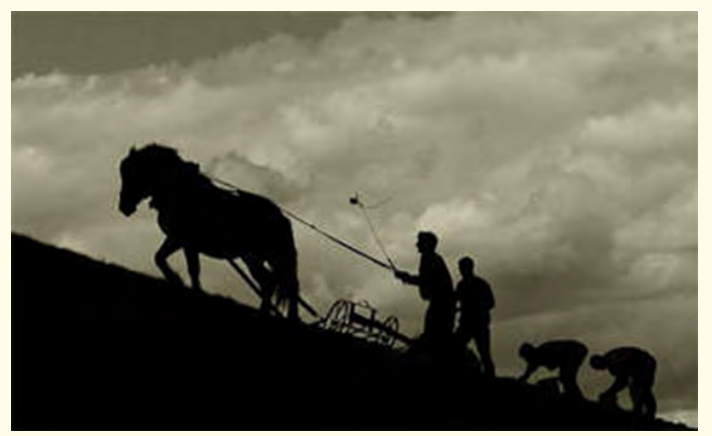

Figure 3
Strategy for rapid agriculture commercialization

The major challenge is to devise the suitable location specific solutions to restore and accelerates the economic process to ensure commercialization. This requires multi-pronged strategy to understand the multifasceted hill region. Devolution of appropriate and meaningful interventions and strategies for development is enabling factor in the effort to understand the complex but lesser known system of hilly area. The prioritization of the strategies of the strategies for commercialization should focus on factor inhibiting the agricultural growth, livelihood and structural infirmity of hilly regions.

- Traditional and modern methods of water and land use plan ning for resource use efficiency and need based accelerated adoption of integrated agri-hortu-silvi-livestock system.

- Maintain cereal productrions for household food securityin accessible terrain but promote crop diversification in favor of high value and low crops of fruit, vegetable, flowers, aro matics and medicinal plants and plantation crops for income supplements.

- Special and exclusive program on hill are infrastructure, marketing and processing for enhancing markability of pro duced crops.

- Promoting and facilitating off season weather sensitive cash crops risk free good quality seedling of vegetables, flowers and even their cultivation in polyhouses should be encour aged.

- Developing and providing simplified pro-farmers credit sup port and crop insurance cover for stepping up the use of in puts and adoption of modern technology.

- Animal husbandry, fisheries and silvi-pastoral programmes must be extended.

- Crop diversification to low yielding rice and millet in the crops with horticultural crops such as plum, pear, peaches with their systematized marketing and processing by devel oping appropriate technologies.

- Infrastructure development and incentives to lure private in vestment.

- Certain disaster preparedness and risk copping mechanism and information need to be transmitted for disaster manage ment.

- Prioritisation of research on appropriate technologies refine ment and development of new technologies.

- Linking farmers with market for remunerative prices har vest oppurtinity through niche commodities in the up markets. 


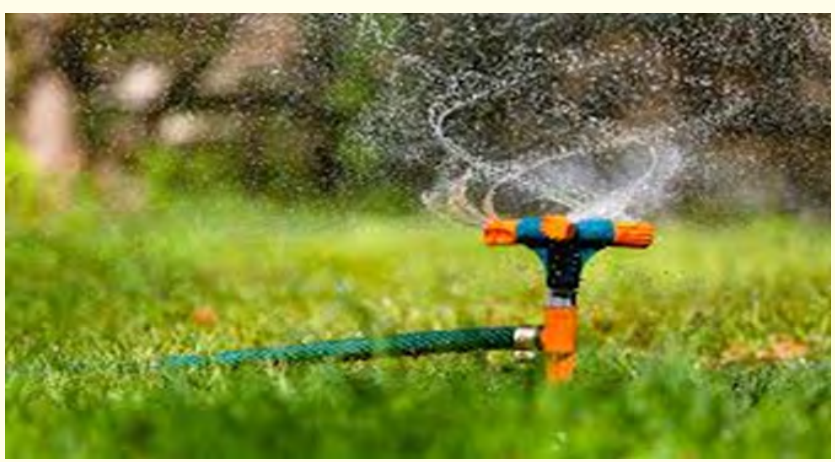

Figure 7

Hilly region of Nepal is characterized by unique ecological entities and topographical diversities required for the agricultural development. There is no option in shifting subsistence agriculture towards commercializationfor improving the rural and agri-based economy of hilly region. Difficult landscapes and lack of infrastructures are creating a problem in agricultural commercialization. Devolution of appropriate and meaningful policy interventions and strategy for commercialization of agriculture in hilly area is most. Thus, the innovative and holistic approach for commercialization of agriculture through synergizing people, institutions, local ecologies and resources use pattern of the hilly region.

Volume 3 Issue 7 July 2019

CC All rights are reserved by Yubraj khanal. 